\title{
The Design of Intelligent Heat Dissipator Control Circuit
}

\author{
Biqing $\mathrm{Li}^{1 \text {, a }}$,Zhao $\mathrm{Li}^{* 2,}$, ,Qiang $\mathrm{Li}^{1 \text {, a }}$ \\ ${ }^{1}$ College of Mechanical and Electronic Engineering, Hezhou university, Hezhou Guangxi \\ 542899, China; \\ ${ }^{2}$ Management Engineering Department, Guangxi vocational and technical college of \\ communications,Liuzhou Guangxi 545000, China; \\ janliful@163.com, b229292710@qq.com
}

Abstract: This page proposed an intelligent radiator which used MCU AT89S52 as the core, mainly consist of temperature and humidity detection part, main control part, display part, control part. Firstly, collect the temperature and humidity of the environment by using DHT11 temperature and humidity sensors. And then sends the data to STC89C52RC computer for analysis and processing. After the data was processing, on the one hand, the data is displayed through the LCD display LCD1602, on the other hand, the data compare to program setting of the temperature and humidity range, to control the heating device, cooling equipment, humidifying device, dehumidifying device and a buzzer. This design has reached all the expected requirements after debugging.

Key words: single chip microcomputer;DHT11;intelligent;temperature and humidity; control systems

\section{Overall Design}

According to the function of the required achievement of subject, the control system can be divided into four parts. The block diagram is as shown in figure 1. The temperature and humidity sensor transforms the detected data from the environment by the modulus, and sends to the microcontroller to carry out the treatment. After accepting the data, and after the analytical processing, the data is displayed on the display screen by the microcontroller. At the same time, the microcontroller makes the comparison of the treated data and the setting range of the temperature and humidity numerical value. If the detected data is in the setting range, that means the control part will not make any reaction. If outside the setting range, the microcontroller will send the low level to the corresponding ends of the control part, so the control part carries out the heating, moisturizing, cooling, air drying and other activities. When the collected temperature and humidity are close to the limit value of the sensor, the control part can send out the alarm, which shows the current environment is very terrible.

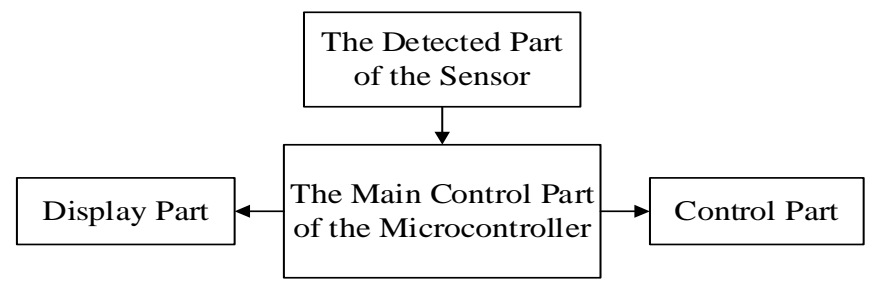

Figure 1 The Block Diagram of the Overall Design

(1) Brief introduction of LCD1602 Liquid crystal display screen

LCD1602 liquid crystal is also called 1602 character type liquid crystal, it is a kind of lattice 
liquid crystal, which specializes in displaying the letters, figures, symbols and others. Its real picture is shown in figure 4 , the pin picture is shown in figure 5 . They are composed by several $5 \times 7,5 \times 11$ or other lattice character bits, every lattice character bit can display one character. There is one interval of dot spacing between two bits, and there is one interval between every line, they play the role of character spacing and line spacing, it can not display the figure because of these reasons.

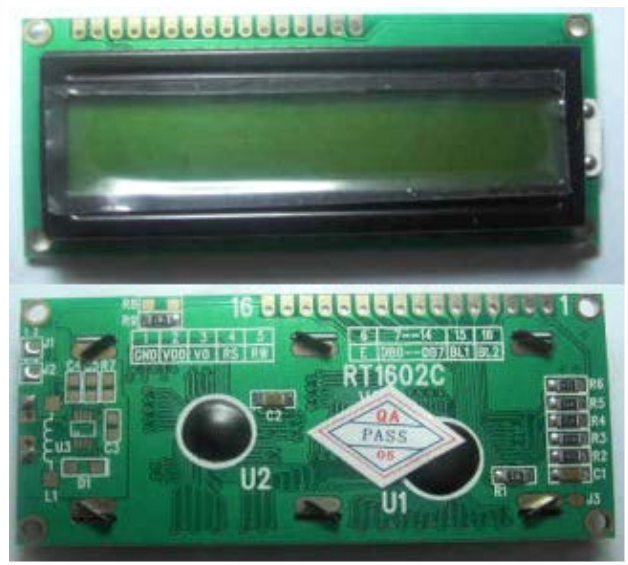

Figure 2 LCD1602 Real Objects

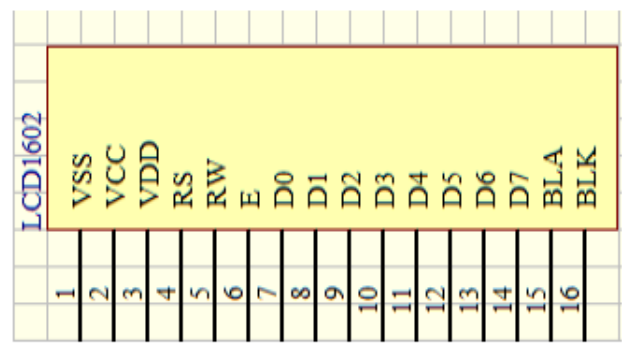

Figure3 LCD1602 Pin Picture

(2) DHT11 temperature and humidity sensor

The measuring range of humidity is $20 \% \sim 90 \% \mathrm{RH}$; the measuring accuracy of humidity is $\pm 5 \% \mathrm{RH}$; the measuring range of temperature is $0 \sim 50{ }^{\circ} \mathrm{C}$, the measuring accuracy of temperature is $\pm 2^{\circ} \mathrm{C}$, the working voltage is $3.0 \sim 5.5 \mathrm{~V}$, the corresponding time is $<5 \mathrm{~S}$, DHT1l is adopted by 4 needles single line pin encapsulation, after the sensor is power on, need to wait $1 \mathrm{~s}$, because need to over the unstable state, during this period, do not need to send out the instruction, can add a 100nF capacitance between the power supply pin (VDD, GND), which is used for decoupling and filtering.

(3) Brief-introduction of the control part components

Due to a various kinds of devices are composed together and used on the control part all can reach to the prospective requirements.The heating part: Carry out the heating for the environment by using the $12 \mathrm{~V}(5 \mathrm{~V}$ heating effect is not obvious) aluminium heating film. The cooling part: Carry out the blowing for the heating film and environment by using the $5 \mathrm{~V}$ small fan, so as to reach to the cooling effect.The moisturizing part: Blow the water vapor to the environment by using the $5 \mathrm{~V}$ sprinkler, so as to reach to the moisturizing effect.The dried part: Carry out the air suction by using the $5 \mathrm{~V}$ exhaust fan, so as to make the environment becomes dry.The alarm part: Use the $5 \mathrm{~V}$ buzzer to give an alarm. 


\section{The minimum system of the microcontroller}

In the control system of microcontroller, reset circuit plays a very important role. When the procedure has an abnormal operation, halting system or we need to recover the system to the original state, so we need to make the reset circuit for the system. We can carry out one key reset by the reset circuit. Connect the reset circuit to the ninth (RST) feet of microcontroller. When the high levels with more than 2 machine cycles are appeared on the ninth (RST) feet, the microcontroller will carry out the reset operation, when it constantly has the high level, the microcontroller will constantly reset.

\subsection{LCD1602 sub-circuit}

In this design, 1 foot VSS is connected the ground, 2 feet VDD is connected the $5 \mathrm{~V}$ power supply, 3 feet $V L$ is the adjusting end of the contrast ratio of liquid crystal display, when connect the positive power supply, the contrast ratio is weakest, when connect the ground, the contrast ratio is highest, when the contrast ratio is high, the ghosting will be appeared, at this moment, can enhance the contrast ratio by connecting a $1 \mathrm{~K}$ resistance.

2.2 DHT11 the sub-circuit of the temperature and humidity sensor

DHT11 and the microcontroller have the simple connection. As shown in figure 12.1 foot is connected the $5 \mathrm{~V}$ power supply, 2 feet DATA is connected the 25 (P2.4) feet of microcontroller. Due to the drive capability is weaker on the microcontroller end, so in this design, a $5 \mathrm{~K}$ pull-up resistor is added on the DATA end of DHT11, and is connected to VCC, so as to increase the drive capability of the P2.4 foot. 3 feet NC is hanged in the air, the 4 feet VDD is connected the ground.

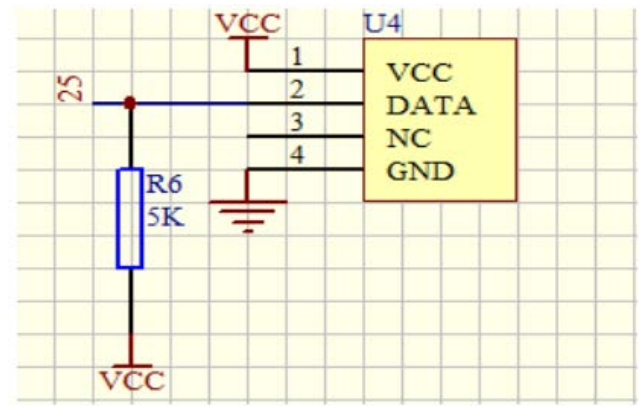

Figure4 DHT11 the Sub-circuit of the Temperature and Humidity Sensor

\subsection{The sub-circuit of the control part device}

At this moment, due to a lot of unused I/O mouths are remained in the microcontroller, the control part devices and the microcontroller can make the free connection. Consider the simple routing problem, in this design, the cooling small fan, heating film, exhaust fan, sprinkler, buzzer are orderly connected to the P1.0、P1.1、P1.2、P1.3、P2.3 of the microcontroller. Because the drive capability on these ends can not drive these devices to have the normal operation, therefore, need to enlarge the end electric current by using the audion.

\subsection{The sub-circuit of keypad}

This design uses the stand alone type keypad. Need to use 4 independent keypads, keypad 1 is the selected keypad, only press this keypad, the other keypads will be valid; keypad 2 is the added keypad, when press once, the range of temperature or humidity will be decreased 1; keypad 4 is the confirmed keypad, which is used for saving the pressed key values by the front 3 keypads. S1、S2、S3、S4 are orderly connected to the 10-13 (P3.0-P3.3) feet of microcontroller, the sub-circuit of keypad is shown in figure 15. 


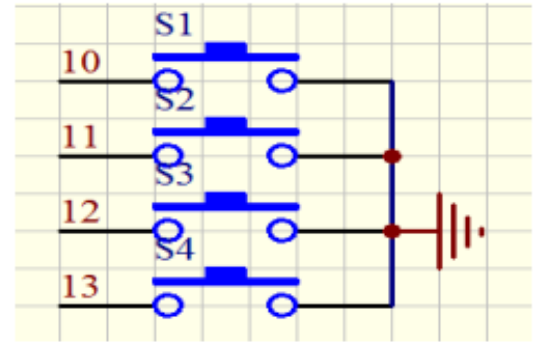

Figure5 The Sub-circuit of Keypad

\section{Debugging and the result}

After completed the hardware and compiled the procedure, the HEX documents can be downloaded to the microcontroller. And in the next step, connect the power supply to carry out the debugging, check whether the result is reached to the prospective requirement. If the data can be accurately displayed, which means the works has reached to a half success.

\section{4 conclusion}

This system not only has the strong practicability, but also has the higher expansibility, which can integrate the clock, calculator, temperature and humidity measurement and others, it has a certain market value.

This work is supported the following fund:2016 The project of improving the basic ability of young teachers in Colleges and universities in Guangxi:"Design and development of electronic commerce platform of agricultural products based on Semantic Technology"(No,KY2016YB455).2015 college students' innovative training program: "Research on the application of value added travel experience in the mobile terminal of the 'ethnic custom travel' in Guangxi" (No 201511838070);\&\& "The design and development HeYuanTong Campus Mobile Phone APP based on Android" (No 201511838034).Project of scientific research and technology development project of Hezhou: "Design and implementation of agricultural products e-commerce platform based on Semantic Technology" (No,Hekeneng 1506006).

\section{Reference}

[1] B.Q LI, Y.F LING, H.Y ZHANG, S.Y ZHENG: The Design and Realization of Cherry Tomato Harvesting Robot Based on IOT. International Journal of Online Engineering, 12(12), 23, (2016).

[2] B.Q LI, W.L GUAN, S.Y Zheng, X.G Yue: OPTIMISATION DESIGN OF CORN PRECISION SEEDER BASED ON MULTI-ROUTE AND MULTI-CHANNEL CONTROL. JOURNAL OF THE BALKAN TRIBOLOGICAL ASSOCIATION, 21(4A), 1215, (2015).

[3]李碧青, 朱强, 郑仕勇, 陈科尹.杂草自动识别除草机器人设计一一基于嵌入式 Web 和 ZigBee 网关.[J]农机化研究.2017.1(1)

[4] B.Q Li, et al, Intelligent Control Management System and Its Application, in: PROCEEDINGS OF THE 2016 INTERNATIONAL CONFERENCE ON ECONOMICS AND MANAGEMENT INNOVATIONS, Wuhan, China, 2016, PP.68-71.

[5] B.Q Li, et al, Design and Implementation of Tanks War Game Based on the Android Platform, in: PROCEEDINGS OF THE 2016 2ND WROKSHOP ON ADVANCED RESEARCH AND TECHNOLOGY IN INDUSTRY APPLICATIONS, Dalian, China, 2016, PP.963-966.

[6] B.Q Li, et al, Design of a Tea Garden Antifreezing Control System, in: PROCEEDINGS OF $\begin{array}{lllll}\text { THE } & 2016 & 6 T H & \text { INTERNATIONAL } & \text { CONFERENCE }\end{array}$ MACHINERY,MATERIALS,ENVIRONMENT,BIOTECHNOLOGY AND COMPUTER(MMEBC), Tianjin, China, 2016, PP.736-738. 
[7] B.Q Li, et al, Design of Electronic Compass, in: PROCEEDINGS OF THE 2016 6TH INTERNATIONAL CONFERENCE ON MACHINERY,MATERIALS,ENVIRONMENT,BIOTECHNOLOGY AND COMPUTER(MMEBC), Tianjin, China, 2016, PP.1240-1243.

[8] B.Q Li, et al, Research of Automatically Light-Adjusting Lamp, in: PROCEEDINGS OF THE 2016 INTERNATIONAL CONFERENCE ON COMPUTER ENGINEERING,INFORMATION SCIENCE \& APPLICATION TECHNOLOGY(ICCIA 2016), Guilin, China, 2016, PP.249-252.

[9] B.Q Li, et al, The Design and Realization of Fruit Harvesting Robot Based on IOT, in: PROCEEDINGS OF THE 2016 INTERNATIONAL CONFERENCE ON COMPUTER ENGINEERING,INFORMATION SCIENCE \& APPLICATION TECHNOLOGY (ICCIA 2016), Guilin, China, 2016, PP.261-264.

[10] B.Q Li, et al, A New Type of Automatic Opening and Closing Light-Operated Curtain, in: PROCEEDINGS OF THE 2016 INTERNATIONAL CONFERENCE ON MECHATRONICS ENGINEERING AND INFORMATION TECHNOLOGY(ICMEIT), Xian, China, 2016, PP.66-69.

[11] B.Q Li, et al, Design of the Intelligent Air Humidifier, in: PROCEEDINGS OF THE 2016 INTERNATIONAL CONFERENCE ON MECHATRONICS ENGINEERING AND INFORMATION TECHNOLOGY(ICMEIT), Xian, China, 2016, PP.201-203.

[12] B.Q Li, et al, The Design Implementation of the APP of Experiencing Guangxi Folk Custom, in: PROCEEDINGS OF THE 2016 INTERNATIONAL CONFERENCE ON ECONOMICS AND MANAGEMENT INNOVATIONS, Wuhan, China, 2016, PP.47-50.

[13] S.Y Zheng, et al, Digital Display Design of Ethnic Clothing of Nanling, in: PROCEEDINGS OF THE 4TH INTERNATIONAL CONFERENCE ON MECHATRONICS,MATERIALS.CHEMISTRY AND COMPUTER ENGINEERING 2015(ICMMCCE 2015), Xian, China, 2015, PP.2805-2808.

[14] S.Y Zheng, et al, Design and Implementation of Supermarket Personnel Management System Based On Java, in: PROCEEDINGS OF THE 2015 INTERNATIONAL CONFERENCE ON EDUCATION,MANAGEMENT AND COMPUTING TECHNOLOGY, Tianjin, China, 2015, PP.1724-1727.

[15] S.Y Zheng, et al, Analysis of Internet of Things Talent Training and Curriculum System Innovation, in: PROCEEDINGS OF THE 2016 INTERNATIONAL CONFERENCE ON EDUCATION,MANAGEMENT AND COMPUTING TECHNOLOGY(ICEMCT-16), Hangzhou, China, 2016, PP.957-960.

[16] S.Y Zheng, et al, Brief analysis on "HeYuanTong"Campus Mobile Phone APP Design, in: PROCEEDINGS OF THE 2015 5TH INTERNATIONAL CONFERENCE ON COMPUTER SCIENCES AND AUTOMATION ENGINEERING, Sanya, China, 2015, PP.151-154.

[17]S.Y Zheng, et al, Social Work in Teen Addiction Correction Services Research Under the New Situation, in: PROCEEDINGS OF THE 2015 4TH NATIONAL CONFERENCE ON ELECTRICAL, ELECTRONICS AND COMPUTER ENGINEEERING(NCEECE 2015), Xian, China, 2015, PP.252-255. 